\title{
Predictors of In-Hospital Outcome in Initially Hemodynamially Stable Adults with Non-STSegment-Elevation Myocardial Infarction
}

\author{
H.K.Rashid, E.S.Elkeshk, S.A.Mostafa and A.S.Hassanien
}

Cardiology, Dept., Faculty of Medicine, Benha Univ., Benha, Egypt

E-mail: Shawky1988@gmail.com

\begin{abstract}
Facts: The ICU utilisation for initially stable patients with non-ST-segment-elevation myocardial infarction (NSTEMI) varies greatly between institutions and correlates weakly with disease severity. ICU resources are limited, yet high-risk patients must be cared for in a safe manner, and this study aims to predict if a patient with NSTEMI who is initially stable is likely to need ICU care. Methods: a cross-sectional investigation with a single central point. This research comprised 500 adult patients of both sexes with NSTEMI who were admitted to the National Heart Institute's coronary care unit for evaluation. 58 percent of our patients were males, with a mean age of 59.4413.89 years old, according to our findings (range: $32-88$ ). As far as their medical history goes, $72 \%$ had hypertension, $58 \%$ had dyslipidemia, $46 \%$ were diabetics, $26 \%$ had a prior heart attack, $24 \%$ had chronic obstructive pulmonary disease, and $14 \%$ were drug abusers. $56 \%$ were smokers, and $56 \%$ had a favourable hospital admission history. Patients with ACTION ICU risk scores ranging from 1 to 14 had a risk of problems needing ICU care of $3.3 \%$ to $39.3 \%$, with a mean value of 20.4813.23. The ACTION ICU score performed better than the GRACE risk score in predicting problems that need ICU treatment. With a cut-off value of $>15$, the Action ICU risk score had an AUC of $0.931,96.2$ percent sensitivity, 91.7 percent specificity, and 92.6 percent positive and negative predictive values. HTN, PCI, CABG, Stroke and PVD were shown to be associated with a higher risk of death. Age (years), HTN, Prior PCI, Prior $\mathrm{CABG}$ and Prior Stroke were also found to be associated with an increased risk of death. We found that 13.6 percent of NSTEMI patients who acquired a state needing ICU-level care died without ever being admitted to the ICU. Conclusion: Among patients with NSTEMI who were hemodynamically stable, the ACTION ICU risk score demonstrated strong capacity to predict the likelihood of developing problems requiring ICU-level care. With this score, hospitals may efficiently minimise the usage of ICU resources while ensuring sufficient care is given to highrisk patients.
\end{abstract}

Key words: Hemodynamiallym, Stable Adults, Non-STSegment, Elevation, Myocardial Infarction

\section{Introduction}

Intensive care unit (ICU) utilisation for patients with non-ST-segment-elevation myocardial infarction (NSTEMI) is very variable amongst hospitals (NSTEMI). To help anticipate the need for intensive care in patients with acute chest discomfort, Goldman et al. [1] established a risk score based on data collected in the 1980s, a time when early invasive treatment was less common. [2].

Recurrent MI, arrhythmia, cardiac failure, shock, blood loss, stroke, and mortality may all be predicted using the GRACE Freedom-From-Events score. [3].

As such, it is the first risk score for NSTEMI in a modern population to predict the requirement for ICU treatment. Variables including age, ST-segment depression, blood pressure, and elevated cardiac biomarkers all contribute to our mortality risk score. This risk score was found to be more accurate than other commonly used risk scores in the population of patients with acute coronary syndromes, such as Thrombolysis in Myocardial Infarction mortality risk score or CRUSADE (Can Rapid Risk Stratification of Unstable Angina Patients Suppress Adverse Outcomes with Early Implementation of American College of Cardiology/ American Heart Association guidelines) bleeding score. Since in-hospital issues necessitating ICU care were not included into the GRACE risk score, it was not surprising that the ACTION ICU score outperformed it. Despite the GRACE risk score's extensive history as a mortality prediction score, its performance for the prediction of ICU-requiring complications has not previously been assessed despite its long history [6]

Patients with NSTEMI who are initially stable but who later develop complications necessitating ICU care may benefit from the adoption of an objective risk assessment technique that may be used to efficiently allocate scarce ICU resources while ensuring that high-risk patients are treated appropriately.

\section{Patients and Methods}

Subjects: Adult patients of both sex with NSTEMI were included

Study design: Single center cross sectional study.

Patients: 500 Patients with NSTEMI who were admitted to the coronary care unit of National heart institute were evaluated in this study

Duration of study: 12 months from January 2019 to January 2020

Inclusion criteria:

- Patients who presented for the first time with ischemic symptoms and NSTEMI.

- Positive cardiac biomarkers Exclusion criteria:

- Cardiogenic shock at presentation

- Chronic kidney disease, Advanced liver disease and respiratory failure

- Unwilling to participate in the study

- Cardiac Arrest at presentation 
We exclude patients with cardiogenic shock and cardiac arrest from the start because of clear requirement of ICU admission at presentation.

\section{Method:}

500 Patients with NSTEMI who were admitted to the coronary care unit of our institution were evaluated in this study. patients were subjected to:

- complete history taking.

- clinical examination including local cardiac and chest examination.

- ECG: A 12-lead ECG with a paper speed of $50 \mathrm{~mm} / \mathrm{s}$ will be recorder at time of admission as well as the immediate after ICU admission.

- Cardiac Biomarkers including CK Total, CK MB and Troponine.

- Echocardiography: using The Philips iE 33 Machine.

2D: Segmental wall motion abnormality was assessed semi quantitatively in parasternal long and short-axis views and apical views. In short-axis views, the LV was divided into 5 segments at the base and at papillary muscle level (anterior and posterior septum; anterior, lateral, and posterior walls) and into 4 segments at the apex (septum, anterior, lateral, and posterior walls).

Pulsed wave Doppler can assess Diastolic dysfunction and its grades, the dynamics of LV filling and their alteration with diastolic dysfunction are noninvasively assessed from Doppler measurement of mitral inflow velocity and tissue Doppler assessment of mitral annular velocity. Under normal circumstances, the peak early mitral inflow velocity (E) substantially exceeds the peak velocity during atrial contraction (A). Thus, the E/A ratio is $>1$.

The Action Icu risk model was designed to predict, at the time of admission, the subsequent development of in-hospital complications requiring ICU care. We defined complications requiring ICU care as cardiac arrest, shock, heart block requiring pacemaker placement, respiratory failure, stroke, or death occurring any time during the hospitalization. These complications were chosen on the basis of clinical judgment and reflect events that frequently require ICU interventions, such as use of vasopressors, mechanical hemodynamic support devices, mechanical ventilation, central venous access, and invasive hemodynamic monitoring.

Nine variables in Action Icu risk model were available on presentation to the emergency department to predict the development of complications requiring ICU care: signs or symptoms of heart failure, initial heart rate, initial systolic blood pressure, initial troponin, initial serum creatinine, prior revascularization, chronic lung disease, ST-segment depression, and age Table (7).

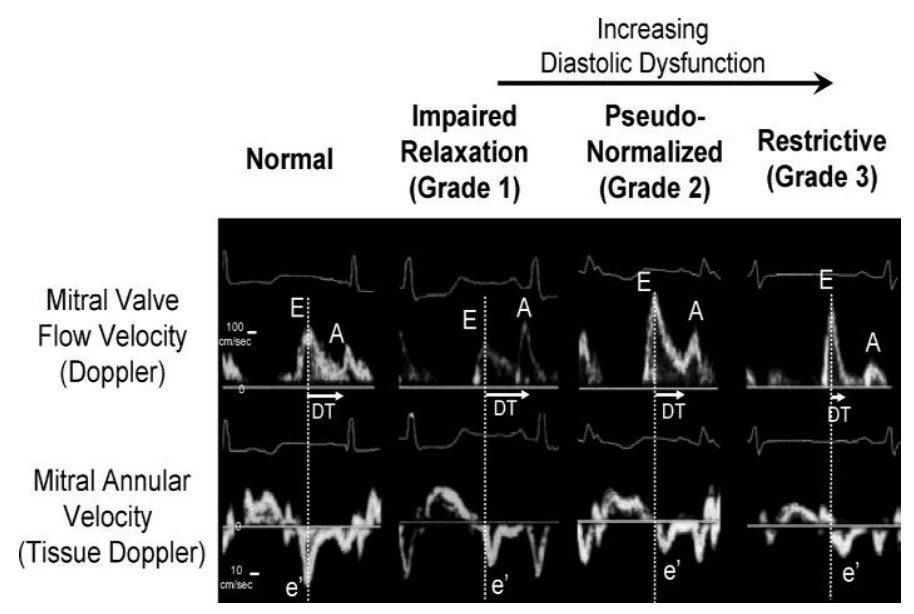

Fig. (4) The stages of diastolic dysfunction recognized by changes in LV filling dynamics

Table (7): Calculation of ACTION ICU Risk Score ${ }^{(7) .}$

\begin{tabular}{|c|c|c|c|c|c|c|c|c|c|}
\hline Age, y & Points & $\begin{array}{l}\text { Serum } \\
\text { Creatinine, } \\
\text { mg/dL }\end{array}$ & Points & $\begin{array}{l}\text { Heart } \\
\text { beats/min }\end{array}$ & Points & $\begin{array}{l}\text { Systolic } \\
\text { Blood } \\
\text { Pressure, } \\
\text { mm Hg }\end{array}$ & Points & $\begin{array}{l}\text { Initial } \\
\text { Troponin, } \\
\text { 9ULN }\end{array}$ & Points \\
\hline$<70$ & 0 & $<1.1$ & 0 & $<85$ & 0 & $<125$ & 3 & $<12$ & 0 \\
\hline$\geq 70$ & 1 & $\geq 1.1$ & 1 & $85-100$ & 1 & $125-145$ & 1 & $\geq 12$ & 2 \\
\hline$\geq 100$ & 3 & $\geq 145$ & 0 & & & & & & \\
\hline $\begin{array}{l}\text { Signs or } \\
\text { Symptoms } \\
\text { of HF }\end{array}$ & Points & $\begin{array}{l}\text { ST } \\
\text { Depression }\end{array}$ & Points & $\begin{array}{l}\text { Prior } \\
\text { Revascularization }\end{array}$ & Points & $\begin{array}{l}\text { Chronic } \\
\text { Lung } \\
\text { Disease }\end{array}$ & Points & & \\
\hline No & 0 & No & 0 & No & 1 & No & 0 & & \\
\hline Yes & 5 & Yes & 1 & Yes & 0 & Yes & 2 & & \\
\hline
\end{tabular}


We used MD Calc Action Icu Risk Score calculator to help identify patients who are initially stable but may later develop complications requiring a higher level of care, and may therefore help with disposition and avoiding failure to rescue, we calculate points and risk percentage of complications requiring ICU care among initially uncomplicated patients with NSTEMI (cardiac arrest, shock, high-grade AV block, respiratory failure, stroke or death during index admission (www.mdcalc.com)

Table (1) Demographic data distribution of the study group

\section{Statistical analysis}

Recorded data were analyzed using the statistical package for social sciences, version 20.0 (SPSS Inc., Chicago, Illinois, USA). Quantitative data were expressed as mean \pm standard deviation (SD). Qualitative data were expressed as frequency and percentage.

\section{Results}

Demographic data distribution of the study group in the table below shows that the female (42\%) and male $(58 \%)$ of sex, while ranged age $32-88$ with mean $59.44 \pm 13.89$, also BMI ranged 22-36 with mean $28.40 \pm 3.84$ (Table 1)

\begin{tabular}{ll}
\hline Demographic data & Total $(\mathbf{n}=\mathbf{5 0 0})$ \\
\hline Sex & \\
Female & $210(42.0 \%)$ \\
Male & $290(58.0 \%)$ \\
Age $($ years $)$ & \\
Range & $32-88$ \\
Mean \pm SD & $59.44 \pm 13.89$ \\
BMI [wt/(ht)^2] & \\
Range & $22-36$ \\
Mean \pm SD & $28.40 \pm 3.84$ \\
\hline
\end{tabular}

Table (2) Medical history distribution of the study group.

\begin{tabular}{ll}
\hline Medical history & Total $(\mathbf{n = 5 0 0})$ \\
\hline DM & $230(46.0 \%)$ \\
HTN & $360(72.0 \%)$ \\
Dyslipidemia & $290(58.0 \%)$ \\
Smoking & $280(56.0 \%)$ \\
Prior MI & $130(26.0 \%)$ \\
Prior HF & $30(6.0 \%)$ \\
Prior PCI & $80(16.0 \%)$ \\
Prior CABG & $30(6.0 \%)$ \\
Prior Stroke & $20(4.0 \%)$ \\
PVD & $70(14.0 \%)$ \\
Chronic Lung Disease & $120(24.0 \%)$ \\
Chronic Live Disease & $40(8.0 \%)$ \\
Hypothyroidism & $60(12.0 \%)$ \\
Drug abuse & $70(14.0 \%)$ \\
\hline
\end{tabular}

Clinical evaluation of the study group in the table below shows that the mean of HR (beat/min) was $95.56 \pm 24.89$, also Systolic blood pressure (mmHg) was mean $120.90 \pm 27.48$, while New or presumed new ST-segment depression 320 (64.0\%) and Chest Pain 460 (92.0\%). (Table 3)

Table (3) Clinical evaluation descriptive of the study group.

\begin{tabular}{ll}
\hline Clinical Presentation & Total $(\mathbf{n}=\mathbf{5 0 0})$ \\
\hline HR (beat/min) & $35-150$ \\
Range & $95.56 \pm 24.89$ \\
Mean \pm SD & \\
Systolic blood pressure (mmHg) & $60-170$ \\
Range & $120.90 \pm 27.48$ \\
Mean \pm SD & $320(64.0 \%)$ \\
New or presumed new ST-segment depression & $460(92.0 \%)$ \\
Chest Pain & \\
\hline
\end{tabular}

The study group laboratory values in the table below shows that the mean of Hemoglobin was 12.18 \pm 1.47 , also Creatinine was mean 1.37 \pm 1.15 ; while CKMB was mean $49.40 \pm 14.35$ and Troponine 410 (82\%). (Table 4) 
Table (4) Initial laboratory values descriptive of the study group.

\begin{tabular}{ll}
\hline Initial laboratory values & Total $(\mathbf{n}=\mathbf{5 0 0})$ \\
\hline Hemoglobin & \\
Range & $8.5-15$ \\
Mean \pm SD & $12.18 \pm 1.47$ \\
Creatinine & \\
Range & $0.5-6$ \\
Mean \pm SD & $1.37 \pm 1.15$ \\
CKMB & \\
Range & $26-90$ \\
Mean \pm SD & $49.40 \pm 14.35$ \\
Troponine & $410(82.0 \%)$ \\
\hline
\end{tabular}

Action ICU risk score of the study group in the table below shows that the mean of action ICU risk score $\%$ was 20.48 \pm 13.23 ; while mean of points was 8.68 \pm 4.94 (Table 5)

Table (5) Action ICU risk score descriptive of the study group.

\begin{tabular}{lc}
\hline & Total $(\mathbf{n = 5 0 0})$ \\
\hline ACTION ICU risk score\% & $3-39.3$ \\
Range & $20.48 \pm 13.23$ \\
Mean \pm SD & \\
Points & $1-19$ \\
Range & $8.68 \pm 4.94$ \\
Mean \pm SD & $(36.9 \%)$, Heart Block $46(17.7 \%)$, RF $40(15.4 \%)$, \\
ospital complication requiring ICU care in the \\
group table [12] shows that the Shock 96
\end{tabular}
study group table [12] shows that the Shock $96 \quad$ Stroke 11 (4.2\%), Arrest 67 (25.8\%). Table (6)

Table (6) Hospital complication requiring ICU care descriptive of the study group.

\begin{tabular}{ll}
\hline Hospital complication requiring ICU care & Total $(\mathbf{n = 2 6 0})$ \\
\hline Shock & $88(34.0 \%)$ \\
HB & $42(16.0 \%)$ \\
RF & $36(14.0 \%)$ \\
Stroke & $11(4.0 \%)$ \\
Arrest & $57(22.0 \%)$ \\
Death & $26(10.0 \%)$ \\
\hline
\end{tabular}

This table shows statistically significant difference between no complication and ICU-requiring complication according to demographic data (Table 7).

Table (7) Comparison between no complication and ICU-requiring complication according to demographic data.

\begin{tabular}{|c|c|c|c|c|}
\hline Demographic data & $\begin{array}{l}\text { No Complication } \\
(n=240)\end{array}$ & $\begin{array}{l}\text { ICU-Requiring } \\
\text { Complication } \\
(\mathbf{n = 2 6 0 )}\end{array}$ & $\mathbf{t} / \mathbf{x} 2 \#$ & p-value \\
\hline \multicolumn{5}{|l|}{ Sex } \\
\hline Female & $90(37.5 \%)$ & $120(46.2 \%)$ & \multirow{2}{*}{ 3.837\# } & \multirow{2}{*}{0.061} \\
\hline Male & $150(62.5 \%)$ & $140(53.8 \%)$ & & \\
\hline \multicolumn{5}{|l|}{ Age (years) } \\
\hline Mean \pm SD & $50.75 \pm 10.68$ & $67.46 \pm 11.48$ & \multirow{2}{*}{282.552} & \multirow{2}{*}{$<0.001 * *$} \\
\hline Range & $32-70$ & $43-88$ & & \\
\hline \multicolumn{5}{|l|}{ BMI $\left[w t /(h t)^{\wedge} 2\right]$} \\
\hline Mean \pm SD & $27.75 \pm 3.38$ & $29.00 \pm 4.13$ & \multirow{2}{*}{13.591} & \multirow{2}{*}{$<0.001 * *$} \\
\hline Range & $22-35$ & $23-36$ & & \\
\hline
\end{tabular}

t-Independent Sample t-test; \# ${ }^{2}$ : Chi-square test

p-value $>0.05 \mathrm{NS}$; *p-value <0.05 S; **p-value <0.001 HS

This table shows statistically significant difference between no complication and ICU-requiring complication according to clinical presentation (Tab 8). 
Table (8) Comparison between no complication and ICU-requiring complication according to clinical presentation.

\begin{tabular}{|c|c|c|c|c|}
\hline Clinical Presentation & $\begin{array}{l}\text { No } \\
\text { Complication } \\
(\mathbf{n}=\mathbf{2 4 0})\end{array}$ & $\begin{array}{l}\text { ICU- } \\
\text { Requiring } \\
\text { Complication } \\
(\mathbf{n = 2 6 0 )}\end{array}$ & $\mathbf{t} / \mathbf{x} 2 \#$ & p-value \\
\hline \multicolumn{5}{|l|}{ HR (beat/min) } \\
\hline Mean \pm SD & $88.04 \pm 11.36$ & $102.50 \pm 31.20$ & & \\
\hline Range & $70-120$ & $35-150$ & 45.909 & $<0.001 * *$ \\
\hline Heart rate $\geq 100$ & $30(12.5 \%)$ & $200(76.9 \%)$ & & \\
\hline \multicolumn{5}{|l|}{ Systolic blood pressure (mmHg) } \\
\hline Mean \pm SD & $143.54 \pm 15.00$ & $100.00 \pm 18.28$ & & \\
\hline Range & $100-170$ & $60-130$ & 840.201 & $<0.001 * *$ \\
\hline Systolic blood pressure $\leq \mathbf{9 0}$ & $0(0.0 \%)$ & $90(34.6 \%)$ & & \\
\hline $\begin{array}{l}\text { New or presumed new ST-segment } \\
\text { depression }\end{array}$ & $70(29.2 \%)$ & $250(96.2 \%)$ & 243.061\# & $<0.001 * *$ \\
\hline Chest Pain & $240(100.0 \%)$ & $220(84.6 \%)$ & 40.134\# & $<0.001 * *$ \\
\hline
\end{tabular}

$\mathrm{t}$-Independent Sample t-test; \# $\mathrm{x}^{2}$ : Chi-square test

p-value $>0.05 \mathrm{NS} ; *$ p-value $<0.05 \mathrm{~S} ; * *$ p-value $<0.001 \mathrm{HS}$

This table shows statistically significant difference between no complication and ICU-requiring complication according to initial laboratory values (Table 9).

Table (9) Comparison between no complication and ICU-requiring complication according to initial laboratory values.

\begin{tabular}{|c|c|c|c|c|}
\hline Initial laboratory values & $\begin{array}{l}\text { No Complication } \\
(\mathrm{n}=\mathbf{2 4 0})\end{array}$ & $\begin{array}{l}\text { ICU-Requiring } \\
\text { Complication } \\
(\mathbf{n = 2 6 0 )} \\
\end{array}$ & $\mathbf{t} / \mathbf{x} 2 \#$ & p-value \\
\hline \multicolumn{5}{|c|}{ 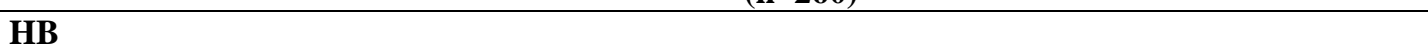 } \\
\hline Mean \pm SD & $12.65 \pm 1.60$ & $11.75 \pm 1.19$ & & \\
\hline Range & $9.8-15$ & $8.5-15$ & 51.299 & $<0.001 * *$ \\
\hline Hb $<13$ & $140(58.3 \%)$ & $240(92.3 \%)$ & & \\
\hline \multicolumn{5}{|l|}{ Creat } \\
\hline Mean \pm SD & $1.23 \pm 1.03$ & $1.51 \pm 1.23$ & & \\
\hline Range & $0.5-5.1$ & $0.7-6$ & 7.671 & $0.006^{*}$ \\
\hline Creat $\geq 1.1$ & $50(20.8 \%)$ & $200(76.9 \%)$ & & \\
\hline \multicolumn{5}{|l|}{ CKMB } \\
\hline Mean \pm SD & $43.38 \pm 10.73$ & $54.96 \pm 15.03$ & & \\
\hline Range & $26-70$ & $33-90$ & 96.989 & $<0.001 * *$ \\
\hline CKMB $\geq 25$ & $240(100.0 \%)$ & $260(100.0 \%)$ & & \\
\hline TROP & $150(62.5 \%)$ & $260(100.0 \%)$ & 118.902\# & $<0.001 * *$ \\
\hline
\end{tabular}

t-Independent Sample t-test; $\# \mathrm{x}^{2}$ : Chi-square test

p-value $>0.05 \mathrm{NS} ; *$ p-value $<0.05 \mathrm{~S} ; * *$ p-value $<0.001 \mathrm{HS}$

This table shows statistically significant difference between no complication and ICU-requiring

complication according to Action ICU risk score (Tab 10).

Table (10) Comparison between no complication and ICU-requiring complication according to action ICU risk score.

\begin{tabular}{lllll}
\hline ACTION ICU risk score & $\begin{array}{l}\text { No Complication } \\
(\mathbf{n = 2 4 0})\end{array}$ & $\begin{array}{l}\text { ICU-Requiring } \\
\text { Complication } \\
(\mathbf{n = 2 6 0 )}\end{array}$ & t-test & p-value \\
\hline $\begin{array}{l}\text { ACTION ICU risk score } \\
\text { Mean } \pm \text { SD }\end{array}$ & $8.12 \pm 3.10$ & $31.89 \pm 7.50$ & 2081.615 & $<0.001^{* *}$ \\
$\begin{array}{l}\text { Range } \\
\text { Points }\end{array}$ & $3-15$ & $17.4-39.3$ & & \\
$\begin{array}{l}\text { Mean } \pm \text { SD } \\
\text { Range }\end{array}$ & $4.17 \pm 1.65$ & $12.85 \pm 2.87$ & 1679.837 & $<0.001^{* *}$ \\
\hline
\end{tabular}

t-Independent Sample t-test; **p-value <0.001 HS 


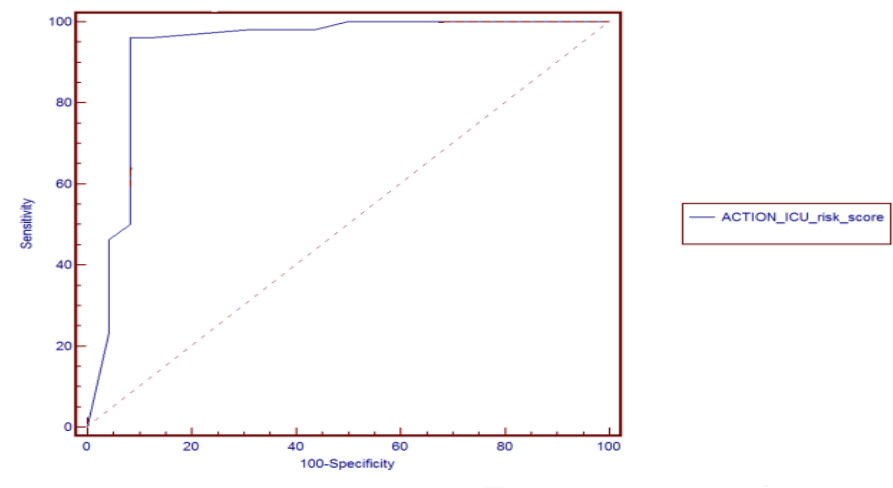

Fig. (1) Receiver-operating characteristic (ROC) curve for prediction of ICU-Requiring complication using the ACTION ICU risk score.

Table (11) Prediction of ICU-Requiring complication using the ACTION ICU risk score.

\begin{tabular}{|c|c|c|c|c|c|c|c|}
\hline Parameters & & Cut-off & Sen. & Spe. & PPV & NPV & $\mathbf{A U C}$ \\
\hline $\begin{array}{l}\text { ACTION ICU } \\
\text { score }\end{array}$ & risk & $>15$ & $96.2 \%$ & $91.7 \%$ & $92.6 \%$ & $95.7 \%$ & 0.931 \\
\hline
\end{tabular}

Receiver operating characteristics (ROC) curve was used to define the best cut off value of:

Action ICU risk score which was $>15$, with sensitivity of $96.2 \%$ specificity of $91.7 \%$ positive predictive value of $92.6 \%$, negative predictive value of $95.7 \%$ with diagnostic AUC of 0.931 (Tab 11 \& fig 1).

\section{Discussion}

Men $(58 \%)$ made up the majority of our patients (59.44\%13.89\%). (range: 32-88). As far as their medical history goes, $72 \%$ had hypertension, $58 \%$ had dyslipidemia, $46 \%$ were diabetics, $26 \%$ had a prior heart attack, 24\% had chronic obstructive pulmonary disease, and $14 \%$ were drug abusers. $56 \%$ were smokers, and $56 \%$ had a favourable hospital admission history.

Non-Structured Myocardial Infarction (NSTEMI)

For patients with acute chest discomfort, the Goldman and colleagues created a risk score, although this model was based on data from the 1980s when early invasive therapy wasn't routinely used. However, a GRACE Freedom-From-Events score has been created to predict unfavourable consequences during hospitalisation. Recurring MI, arrhythmia, cardiac failure, shock, haemorrhage, stroke, and death are among the side effects. There is no need for ICU-level treatment for individuals who acquire this consequence unless they are hemodynamically stable. However, despite the development of several mortality risk scores, none of them were focused at predicting ICU-related complications, which are either lethal or not (8). (9). For NSTEMI patients today, the ACTION ICU risk score is the first to address this problem.

Action ICU risk score was shown to be superior to other frequently used risk ratings for acute coronary syndromes in a research published in the journal Circulation. The other scores that were utilised were: Thrembolysis in Myocardial Infarction (C-statistic,
0.65) or the CRUADE (Can Rapid Risk stratification of Unstable angina patients Suppress Adverse outcomes with Early application of the American College of Cardiology/American Heart Association recommendations) bleeding risk score (C- statistic, 0.71). Ten percent of patients who had ACTION ICU risk scores 1 required ICU treatment, with a mean of 20.4813.23, and the risk of problems varied from 3 percent to 39 percent for those who had risk scores ranging from 14 to 14 . Unlike Goldman et al., where the risk varied from 3.4 to 39.3 percent, the findings of this study show that the risk is lower.

The ACTION ICU score performed better than the GRACE risk score in predicting problems that need ICU treatment. In contrast to Goldman et al's research, the Action ICU risk score cut-off value of $>15$ showed a sensitivity of 96.2 percent, specificity of 91.7 percent, a positive predictive value of 92.6 percent, and a negative predictive value of 95.7 percent. As Brieger et al. argued, (4) the GRACE risk score may be able to identify a low-risk cohort since patients who are at risk of mortality are also more likely to develop additional in-hospital problems, and so the current GRACE risk score may be adequate to identify a low-risk population. There is an apparent association between ACTION ICU risk scores and GRACE percent scores $(\mathrm{r}=0.372, \mathrm{P}=0.001)$, using Pearson Correlation Coefficient.

Regarding the discriminatory value of the other available models; the TIMI UA/ NSTEMI model by Morrow et al., (11) (death, MI, or urgent 
revascularization within 14 days; published c statistic $=0.65)$, TIMI STEMI model developed by Antman et al., (10) (death within 30 days; published $\mathrm{c}$ statistic = 0.78), PURSUIT model developed by Morrow et al., (11) (death within 30 days; published $\mathrm{c}$ statistic = 0.81 ), and GRACE in-hospital mortality model by Boersma et al., (12) (in-hospital death; published c statistic $=0.83)$.

We built a multivariable model of the development of complications that need ICU care in the hospital in order to establish the extra predictive value of the additional parameters. HTN, PCI, CABG, Stroke and PVD were shown to be associated with a higher risk of death. Age (years), HTN, Prior PCI, Prior CABG and Prior Stroke were also found to be associated with an increased risk of death. The findings of Granger et al. contradict this. (8)

According to our findings, a whopping 13 percent of NSTEMI patients with complications necessitating ICU treatment died before ever being admitted. If the patient had been brought to the ICU sooner rather than later, several of these fatalities may have been "preventable," even if the patient had been given a do not resuscitate order.

Using a risk-based approach to health resource use

In order give an advanced hemodynamic monitoring, a $1: 1$ or $1: 2$ nursing to patient ration staffing rations were used in the ICUs, and life sustaining mechanical cardio-respiratory support. This results in a 35 percent expense burden on the hospital with just 5 percent capacity in ICUs. (13) (14)

\section{Conclusion}

The ACTION ICU risk score showed a good predictive ability regarding the prediction the risk of developing complications that require ICU-level care among hemodynamically patients with NSTEMI. With this score, hospitals may efficiently minimise the usage of ICU resources while ensuring sufficient care is given to high-risk patients.

\section{References}

[1] AC.Fanaroff, ED.Peterson, AY.Chen, L.Thomas, JA.Doll, CB.Fordyce, LK.Newby, EA.Amsterdam, MN.Kosiborod, JA.de Lemos, TY.Wang, Intensive care unit utilization and mortality among Medicare

[8] myocardial infarction. JAMA Cardiol.vol.2,pp.36-44,2017.

[9] CB.Granger, RJ.Goldberg, O.Dabbous, Predictors of hospital mortality in the Global Registry of Acute Coronary Events. Arch Intern Med.vol.163,pp.2345-53,2003.

[10] CT.Chin, AY.Chen, TY.Wang, KP.Alexander, R.Mathews, JS.Rumsfeld, CP.Cannon, GC.Fonarow, ED.Peterson, MT.Roe, Risk adjustment for in-hospital mortality of contemporary patients with acute myocardial infarction: the Acute Coronary Treatment and Intervention Outcomes Network (ACTION) Registry_Get With The patients hospitalized with non-STsegment elevation myocardial infarction. JAMA Cardiol.vol.2,pp.36-44,2017.

[2] L.Goldman, EF.Cook, PA.Johnson, DA.Brand, GW.Rouan, TH.Lee, Prediction of he need for intensive care in patients who come to the emergency departments with acute chest pain. N Engl J Med.vol.334,pp.1498-1504,1996.

[3] D.Brieger, KA.Fox, G.FitzGerald, KA.Eagle, A.Budaj, A.Avezum, CB.Granger, B.Costa, FA.Anderson, PG.Steg, Predicting freedom from clinical events in non-ST-elevation acute coronary syndromes: The Global Registry of Acute Coronary Events. Heart.vol.95,pp.888-894,2009.

[4] EM.Antman, M.Cohen, PJ.Bernink, CH.McCabe, T.Horacek, G.Papuchis, B.Mautner, R.Corbalan, D.Radley, E.Braunwald, The TIMI risk score for unstable angina/non-ST elevation MI: a method for prognostication and therapeutic decision making. J Am Med Assoc.vol.284,pp.835-842,2000.

[5] S.Subherwal, RG.Bach, AY.Chen, BF.Gage, SV.Rao, LK.Newby, TY.Wang, WB.Gibler, EM.Ohman, MT. Roe, Baseline risk of major bleeding in non-ST-segment-elevation myocardial infarction. Circulation.vol.119,pp.1873-1882,2009.

[6] R.Chen, KM.Strait, K.Dharmarajan, SX.Li, I.Ranasinghe, J.Martin, R.Fazel, FA.Masoudi, CR.Cooke, BK.Nallamothu, Hospital variation in admission to intensive care units for patients with acute myocardial infarction. Am Heart J.vol.170,pp.1161$1169,2015$.

[7] AC.Fanaroff, ED.Peterson, AY.Chen, L.Thomas, JA.Doll, CB.Fordyce, LK.Newby, EA.Amsterdam, MN.Kosiborod, JA.de Lemos, TY.Wang, Intensive care unit utilization and mortality among Medicare patients hospitalized with non-STsegment elevation

Guidelines (GWTG)TM acute myocardial infarction mortality model and risk score. Am Heart J.vol.161,pp.113-122,2011.

[11] EM.Antman, M.Cohen, PJ.Bernink, CH.McCabe, T.Horacek, G.Papuchis, B.Mautner, R.Corbalan, D.Radley, E.Braunwald, The TIMI risk score for unstable angina/non-ST elevation MI: a method for prognostication and therapeutic decision making. J Am Med Assoc.vol.s284,pp.835-842,2000.

[12] DA.Morrow, JC.Fang, DJ.Fintel, CB.Granger, JN.Katz, FG.Kushner, JT.Kuvin, J.Lopez-Sendon, D.McAreavey, 
B.Nallamothu, Evolution of critical care cardiology: transformation of the cardiovascular intensive care unit and the emerging need for new medical staffing and training models.

Circulation.vol.126,pp.1408-1428,2012.

[13]E.Boersma, KS.Pieper, EW.Steyerberg, for the PURSUIT Investigators Predictors of outcome in patients with acute coronary syndromes without persistent ST-segment elevation: Results from an international trial of $9461 \quad$ patients. Circulation.vol.101,pp.2557-67,2000.
[14] JAD.Molina, E.Seow, BH.Heng, WF.Chong, B.Ho, Outcomes of direct and indirect medical intensive care unit admissions from the emergency department of an acute care hospital: a retrospective cohort study. BMJ Open.vol.4,pp.e005553,2014.

[15] O.Chioncel, A.P.Ambrosy, D.Filipescu, S.Bubenek, D.Vinereanu, A.Petris, M.Gheorghiade, Patterns of intensive care unit admissions in patients hospitalized for heart failure: insights from the RO-AHFS registry. Journal of Cardiovascular Medicine.vol.16(5), pp.331-340,2015. 